\title{
The Influence of Public Support for Innovations on the Economic Performance of Enterprises
}

\author{
Viktorie Klímová
}

Masaryk University, Faculty of Economics and Administration, Czech Republic Vladimír Žítek

Masaryk University, Faculty of Economics and Administration, Czech Republic Tereza Lelková

Masaryk University, Faculty of Economics and Administration, Czech Republic

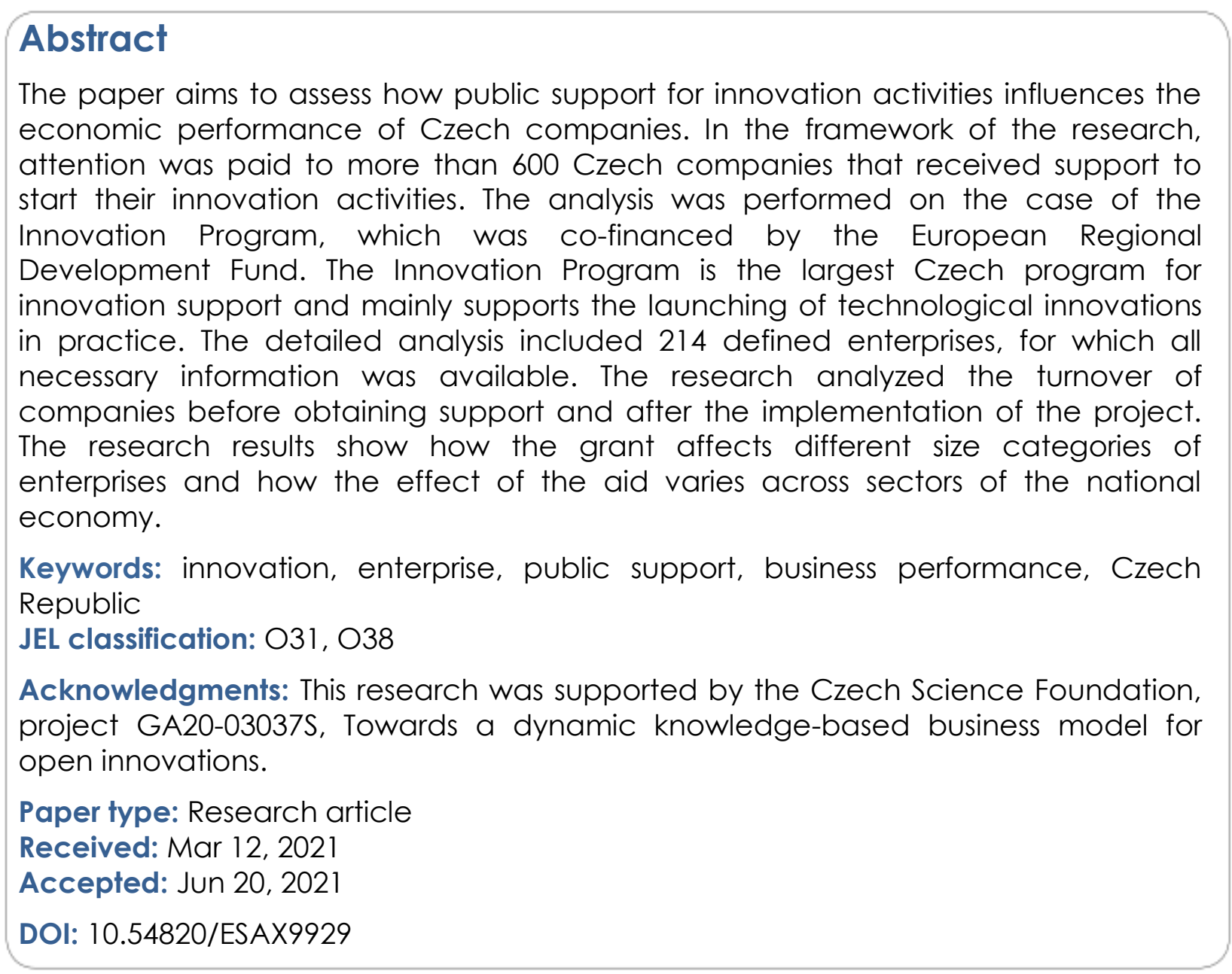




\section{Introduction}

Innovation plays a crucial role in achieving economic growth in developed countries. Therefore, the launching of innovation in companies is an important prerequisite for increasing their competitiveness and represents a competitive advantage that can hardly be replaced in any other way. If enterprises have good conditions to innovate, it has significant positive effects on the socio-economic development of regions and countries. However, the innovation activity of companies is limited by several different barriers. These obstacles reduce or slow down the innovation process and negatively affect regions and states' innovation performance. Barriers to innovation can be defined as external and internal factors that hamper companies' ability to be innovative (Segarra-Blasco et al., 2008). Barriers to innovation are identified mainly in statistical surveys of innovation. Therefore, in empirical research studies, barriers are usually divided into economic, knowledge, market, and other reasons for not innovating (OECD, 2005). Economic barriers are among the most important of them and the main economic barrier is the lack of financial resources for innovation activities (Klímová et al., 2017, Mina et al., 2021).

Governments usually design specialized innovation support programs to eliminate economic barriers and the lack of financial resources for businesses. Research studies on the justification of innovation policy typically rely on two main argumentation approaches, which are market failures and system failures (e.g., Grillo et al., 2011; Dodgson et al., 2011, Bleda et al.o, 2013;). The neoclassical argument about market failure says that the market mechanism, or perfect competition, does not ensure the optimal allocation of resources. There are three reasons for market failures arising: indivisibilities, appropriability, and uncertainty (Arrow, 1962). In the framework of innovation policy, these problems cause that new knowledge or information that is necessary for innovation has a character of a public good. As a result, companies invest fewer resources in research and innovation activities than would be socially desirable. Representatives of institutional approaches complement some other failures contributing to low innovation performance and requiring public policy intervention. These failures are often referred to as system failures and have been elaborated in more detail by Woolthuis et al. (2005). System failures include institutional failures, interaction failures, capability failures, and infrastructural failures.

Our paper contains the analysis of a Czech program that is focused on innovation enhancement. This program supports the implementation of innovation in practice, not R\&D activities. Supported innovations can take the form of product or process innovations (see e.g., OECD, 2005). The primary target group of the evaluated program is companies operating in the manufacturing industry, and therefore our analysis focuses on this segment of companies. The paper aims to assess how public support for innovation activities influences the economic performance of the supported companies.

\section{Support for innovation activities in companies}

Support for innovation activities is focused on introducing innovations into practice, i.e., into production. Product and process innovations are most often supported, and marketing and organizational innovations are usually subsidized in connection with them. Supporting the innovation activities has many features in common with direct support for research activities. It is usually implemented as program support, in which calls for projects are announced and individual projects compete with each other for funding. Innovation support is usually provided in the form of subsidies, and other instruments (loans, guarantees) are less common. 
However, there are also some pitfalls associated with selecting projects to support. More innovative companies are more likely to apply for subsidies, and at the same time, more innovative companies are more likely to receive the offered sources because they better meet the criteria of government agencies. In the literature, the first effect is often referred to as "self-selection of firms". The latter is connected with administrative selection and is referred to as "cream-skimming" (e.g., Curran et al., 2002, Merito et al., 2010).

Most research studies focus on the evaluation of R\&D support programs in companies (e.g., Montmartin et al., 2015; Crespi et al., 2016). Research and development is an important source of knowledge that can be applied in practice through innovation. It is necessary to say that there is no equation between R\&D and innovation. Not every research result is transformed into innovation, and not every innovation is based on research and development. However, radical innovations are usually the result of research activities (e.g., Coccia, 2017). Radical innovations represent completely new products that have not yet been on the market. As Lewczuk et al. (2020) stated, public support for crucial innovations is a way of creating institutional incentives for the desired behavior of firms.

Galbraith et al. (2017) dealt with innovation programs for SMEs in peripheral regions in Northern Ireland (UK). They focused their attention on absorptive capacity (i.e., the ability of the firm to identify, and value, assimilation and exploit external information). Zakić et al. (2020) argue that innovative firms can gain more market share and achieve higher growth. According to them, investing in innovation has a positive impact on business revenues and income increase.

A study conducted for the UK government (BEIS, 2017) investigated the impact of direct support for innovation on companies' survival, employment, and tur, nover. The analysis showed a significant positive impact on the survival rate of companies, with greater effects observed in young companies. The support provided also had a positive impact on the employment and turnover of the supported companies. The impact on employment, in particular, was statistically significant. When expressing employment in the number of new employees, greater impacts were observed in older than younger companies. But this is of course caused by the fact that young companies are usually small.

Neméthová et al. (2019) examined the effectiveness of subsidy support for innovation and the optimal amount of aid in less developed regions in Slovakia. They demonstrated the support has a positive and significant impact on labor productivity that disappears shortly after one year following subsidy allocation. At the same time, they found that the majority of supported firms could benefit from larger subsidy sizes and that the optimum level is set around EUR 2 million. Douglas et al. (2020) examined the joint impact of regional and national funding on firms in the manufacturing industry in Spain concerning cooperative relationships. They found out that for SMEs, a multilevel policy mix has a synergistic effect on cooperation with customers.

\section{Methodology}

In our paper, we analyze the projects of companies that were supported in the framework of the Czech Innovation Program. This program is part of the Operational Program Enterprise and Innovation for Competitiveness 2014-2020, which is cofinanced by the European Regional Development Fund (ERDF). The Innovation Program supports the launching of product and process innovations into practice. The supported projects can be implemented in the territory of the Czech Republic 
except for Prague. Details about the program can be found on the website of its implementation agency (API - Business and Innovation Agency, 2021).

Six calls for innovative projects have been under this program. However, we have included in our analysis only the first three calls, which were announced between 2015 and 2017, so that it is possible to evaluate the supported companies with a certain time lag. Only for these projects, it was already possible to assess the first results. Based on data from the Ministry of Regional Development CZ (2021), a database of 623 supported projects were created. Subsequently, the project database was supplemented with data on companies from the MagnusWeb database (Bisnode, 2021).

Projects whose implementation was prematurely terminated either by the company itself (the beneficiary) or by the managing authority (Czech Ministry of Industry and Trade) were excluded from this data set. Thus, 518 implemented projects remained. Subsequently, only projects implemented by enterprises whose main activity is the manufacturing industry were selected. After this elimination, 457 projects remained in the database. We only wanted to include companies that received support in 2017 and earlier so that their performance could be evaluated over time. It means that we selected projects whose implementation began in the period from 2015 to 2017, and as a result, 370 projects remained in the data set. Furthermore, we had to exclude projects for which not all economic data were available (turnover and number of employees). We were able to include 276 supported projects in the analysis.

For each company, we investigated its turnover a year before receiving the aid and two years after the granting. We, therefore, assessed the change in turnover over the three years under review. We performed the analysis according to the size category of companies and the industry in which they operate. We distinguish between small enterprises (0-49 employees), medium-sized enterprises (50-249 employees), and large enterprises (more than 250 employees). The industry is defined according to the NACE Rev. 2 classification. 2 (Eurostat, 2021), and our attention is focused only on the manufacturing industry (section C, divisions 10-33).

\section{Results and discussion}

Following the methodology described above, the analysis is focused on 276 companies that implemented a project co-financed from the Innovation program. The total amount of subsidy provided to these companies amounted to CZK 3,789.4 million. However, individual beneficiaries drew different amounts of support, ranging from CZK 1 to 100 million (see Table1). In more than $90 \%$ of projects, the support amounted is fewer than CZK 30 million, i.e., up to EUR 1 million. If we compare this fact with the above statement of Neméthová et al. (2019), the support provided is relatively low, and the effects achieved may not be as high.

Table 1

The amount of subsidy provided to support innovation activities (in CZK)

\begin{tabular}{lrlr}
\hline MIN & $1,004,608$ & Median & $7,778,425$ \\
\hline MAX & $100,000,000$ & Average & $13,729,727$ \\
\hline
\end{tabular}

Source: authors' processing based on Ministry of Regional Development CZ (2021)

The tablel is rather informative, and due to the limited scope of the paper, we no longer work with it. Only the fact that the aid was granted is considered. It is 
associated with positive societal expectations and stimulating effects on business performance.

To achieve the defined aim, it is necessary to modify the basic data set before the next procedure. The primary calculation showed that not all companies grew in turnover in the period defined by the methodology, which does not meet the basic assumption of evaluation. There are 62 enterprises with negative growth in turnover within the investigated group, i.e., $22.46 \%$ of them. Most of them belong to the category of small enterprises and micro-enterprises $(26.47 \%)$. On the contrary, the lowest share of such companies was detected among large enterprises (16.90\%). The share of such cases in individual groups of companies is shown in Figure 1.

Figure 1

Number of enterprises with increasing or decreasing turnover $(n=276)$

Small enterprises

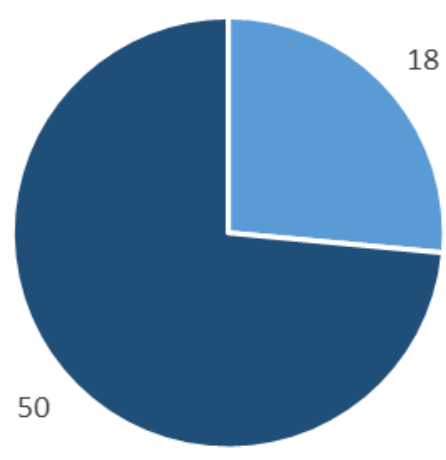

- decrease increase
Medium enterprises

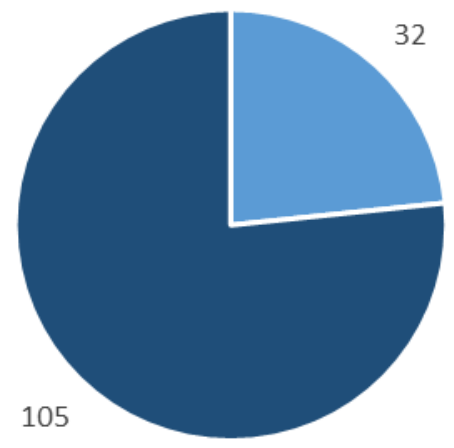

- decrease increase
Large enterprises

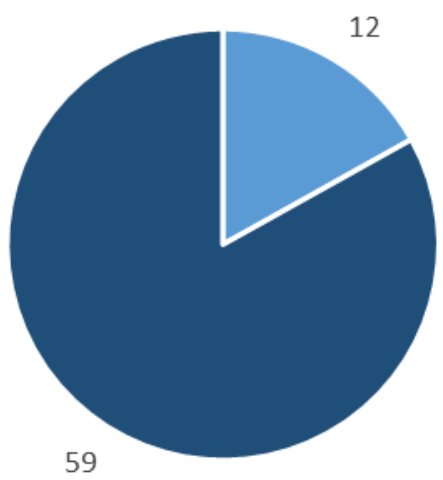

- decrease increase

Source: authors' own based on Ministry of Regional Development CZ (2021)

The key question for the presentation and interpretation of the results was whether it is appropriate to work with average values. Concerning the fact that the observed values for the percentage increase in turnover show significant differences between the year before the aid granting and the second year after it, the use of averages would lead to distorted conclusions. Therefore, the median values are monitored and these values are supplemented by the boundary values of the first and third quartiles. This gives a good picture of the maximum percentage growth achieved by a quarter, a half, and three-quarters of the companies in a given category. Such an approach will also allow a relevant comparison to be carried out between the group.

Table 2 shows how big are the differences in turnover growth among the size groups of companies. Medium-sized enterprises reached the highest increase at the level of the first quartile. The value of $14.14 \%$ is slightly higher than in the case of small enterprises. On the contrary, this value is significantly higher than in the case of large enterprises. From other values in the table, it can be seen that the group of mediumsized enterprises does not show such significant internal differences, as the median value is already lower than for small enterprises and the third quartile limit even significantly lower (by more than ten percentage points). On the other hand, large companies did not experience such significant growth, which is generally mainly due 
to higher initial values of turnover in the year before the subsidy granting, as is the case for smaller companies.

Table 2

Relationship between public support and performance of enterprises - the percentage of turnover growth (according to the size of enterprises)

\begin{tabular}{lcccc}
\hline $\begin{array}{l}\text { Size of } \\
\text { enterprises }\end{array}$ & \multicolumn{1}{c}{ 1st quartile } & median & 3rd quartile & $\begin{array}{l}\text { Number of } \\
\text { enterprises }\end{array}$ \\
\hline Small & 13.29 & 28.47 & 56.31 & 50 \\
Medium & 14.14 & 26.66 & 46.13 & 105 \\
\hline Large & 6.87 & 17.89 & 38.04 & 59 \\
\hline
\end{tabular}

Note: The small enterprises' group also includes micro-enterprises (0-9 employees)

Source: authors' own based on Ministry of Regional Development CZ (2021)

Table 3

Relationship between public support and performance of enterprises - the percentage of turnover growth (according to the NACE division code)

\begin{tabular}{|c|c|c|c|c|}
\hline $\begin{array}{l}\text { NACE (code) } \\
\text { Section C }\end{array}$ & $1^{\text {st }}$ quartile & median & $3^{\text {rd }}$ quartile & $\begin{array}{l}\text { Number of } \\
\text { enterprises }\end{array}$ \\
\hline 10 & 14.99 & 37.42 & 48.32 & 3 \\
\hline 13 & & 1195.74 & & 2 \\
\hline 16 & 16.02 & 36.70 & 88.48 & 6 \\
\hline 17 & 1.27 & 23.99 & 107.87 & 4 \\
\hline 18 & & 11.94 & & 1 \\
\hline 19 & & 22.06 & & 1 \\
\hline 20 & 4.31 & 20.67 & 41.90 & 7 \\
\hline 21 & 6.36 & 19.66 & 60.69 & 4 \\
\hline 22 & 16.03 & 38.11 & 105.60 & 19 \\
\hline 23 & 10.35 & 17.41 & 44.38 & 9 \\
\hline 24 & 1.01 & 12.56 & 22.29 & 10 \\
\hline 25 & 12.91 & 27.41 & 41.30 & 51 \\
\hline 26 & 15.90 & 30.16 & 72.01 & 10 \\
\hline 27 & 20.58 & 33.01 & 43.67 & 12 \\
\hline 28 & 10.68 & 18.65 & 43.39 & 42 \\
\hline 29 & 10.08 & 31.72 & 55.54 & 10 \\
\hline 30 & 25.50 & 30.39 & 99.74 & 7 \\
\hline 31 & 8.24 & 24.28 & 32.85 & 7 \\
\hline 32 & 12.34 & 27.25 & 37.37 & 8 \\
\hline 33 & & 22.54 & & 1 \\
\hline
\end{tabular}

Note: Empty fields are cases where the group includes less than three enterprises. NACE division code - see Eurostat (2008).

Source: authors' own based on Ministry of Regional Development CZ (2021)

Concerning the evaluation of the effect of public support on the economic performance of enterprises, not only the size of enterprises is interesting, but also the industry in which they operate (i.e., sections within the Nomenclature of Statistics on Economic Activities in the European Community (NACE) - see Eurostat (2008)). For section C - Manufacturing, these are divisions 10-33. Section C consists of 20 divisions, as shown in Table 3. Some groups include a very small number of companies, so the results are difficult to interpret. If there are fewer than three enterprises in a division group, the values of the first and third quartiles cannot be calculated. Most companies operate in divisions C25 (Manufacture of fabricated metal products, except machinery and equipment), C28 (Manufacture of machinery and equipment n.e.c.), C22 (Manufacture of rubber and plastic products), and C27 
(Manufacture of electrical equipment). In all other sections, there are always only ten or fewer companies.

A more detailed comment should be given to the two most represented groups, i.e., divisions C25 and C28. These groups cover 93 subsidized companies, which means $43.5 \%$ of those that reached an increase in turnover in the context of the defined conditions. In group C25, half of the companies achieved growth of up to $27.41 \%$. In the third quartile, there are companies with a growth of turnover of up to $41.30 \%$. From this point of view, the median value in the C28 group reached a significantly lower value (18.62\%), while companies in the third quartile approached the limit of $43.39 \%$.

The limitation of our research is as follows. Carrying out the analysis brought several partial obstacles that had to be eliminated. It was mainly a modification of the primary data set and further elimination of the number of analyzed cases so that it is possible to work with them. Therefore, from the original set, which included more than 600 companies, 214 companies remained in the end, which could be assessed in detail. The main reason for this reduction was the unavailability of data characterizing the economic activity of the enterprises. In the later analytical phase, the fact that not all companies increased their turnover played a role.

Nevertheless, the evaluated number of enterprises can be considered sufficiently representative in terms of the representation of enterprise size groups and analysis at the level of the main economic activity according to the NACE classification. The fact that public support for innovation has had a positive effect on the economic performance of companies can be considered proven. It was often a significant increase in turnover over several years, to which this support contributed.

\section{Conclusion}

The paper aimed to evaluate how public support for innovation financed from the EU and provided through the Innovation program contributes to increasing the turnover of companies in the Czech Republic. Although it was only possible to evaluate the data monitored immediately after the aid was granted, it has already been shown that the required effects are significant for the vast majority of companies.

Within the most numerous group of medium-sized enterprises, half of the companies achieved up to $26.66 \%$ higher turnover than in the year before the aid was granted. Several companies in all groups achieved more than $50 \%$ growth in turnover. In small companies, the third quartile was detected to be even $56.31 \%$. It means that a quarter of small companies achieved an even higher increase in turnover.

The results focused on the main activity of enterprises according to divisions of the NACE classification are quite interesting too. Most of the companies in the monitored group operate in divisions C25 (Manufacture of fabricated metal products, except machinery and equipment) and C28 (Manufacture of machinery and equipment n.e.c.). More than a quarter of companies achieved a turnover increase of $40 \%$ and more in both groups.

Although we perceive the results already valuable in this form, several open questions remain and need further attention. In particular, it is a regional dimension of research. It would be possible to analyze the impacts of public support in terms of the place of project implementation and thus contribute to a broader discussion of regional policy impact assessment. Another direction of research is evaluating the closer link between the amount of the subsidy provided and the rate of increase in 
turnover, which would enrich the conclusions of some other research studies dealing with the optimization and effectiveness of public support.

\section{References}

1. API - Business and Innovation Agency (2021), "General Information on OP EIC", available at: https://www.agentura-api.org/en/op-pik-obecne (20 April 2021)

2. Arrow, K. J. (1962), "Economic welfare and the allocations of resources of invention", in The Rate and Direction of Inventive Activity: Economic and Social Factors, Princeton University Press, Princeton, pp. 609-626.

3. BEIS (2017), "The impact of public support for innovation on firm outcomes", BEIS Research Paper, No. 3. BEIS, Department for Business, Energy \& Industrial Strategy, London, March 2017.

4. Bisnode (2021), "MagnusWeb", available at: https://magnusweb.bisnode.cz (15 January 2021)

5. Bleda, M., del Río, P. (2013), "The market failure and the systemic failure rationales in technological innovation systems", Research Policy, Vol. 42 No. 5, pp. 1039-1052.

6. Coccia, M. (2017), "Sources of technological innovation: Radical and incremental innovation problem-driven to support competitive advantage of firms", Technology Analysis, Vol. 29 No. 9, pp. 1048-1061.

7. Crespi, G., Giuliodori, D., Giuliodori, R., Rodriguez, A. (2016), "The effectiveness of tax incentives for R\&D+i in developing countries: The case of Argentina", Research Policy, Vol. 45 No. 10, pp. 2023-2035.

8. Curran, J., Storey, D. J. (2002), "Small business policy in the United Kingdom: the inheritance of the Small Business Service and implications for its future effectiveness", Environment and Planning C: Government and Policy, Vol. 20, pp. 163-177.

9. Dodgson, M., Hughes, A., Foster, J., Metcalfe, S. (2011), "Systems thinking, market failure, and the development of innovation policy: The case of Australia", Research Policy, Vol. 40 No. 9, pp. 1145-1156.

10. Douglas, D., Radicic, D. (2020), "Network additionality and policy mix of regional and national public support for innovation", Economics of Innovation and New Technology, DOI: 10.1080/10438599.2020.1789277.

11. Eurostat (2008), "NACE Rev. 2 - Statistical classification of economic activities", available at: https://ec.europa.eu/eurostat/en/web/products-manuals-and-guidelines/-/KS-RA-07015 (20 April 2021)

12. Galbraith, B., McAdam, R., Woods, J., McGowan, T. (2017), "Putting Policy into Practice: An Exploratory Study of SME Innovation Support in a Peripheral UK Region", Entrepreneurship and Regional Development, Vol. 29 No. 7-8, pp. 668-691.

13. Grillo, F., Landabaso, M. (2011), "Merits, problems and paradoxes of regional innovation policies", Local economy, Vol. 26 No. 6-7, pp. 544-561.

14. Klímová, V., Winklerová, L. (2017), "Bariéry pro rozvoj inovací v regionech (Barriers to innovation development in regions)", in Klímová, V., Žítek, V. (Eds.), 20th International Colloquium on Regional Sciences, Masaryk University, Brno, Czech Republic, pp. 246-254.

15. Lewczuk, A., Lewkowicz, J. (2020), "Incentives for Private Innovations - Is Public Support Necessary?", Argumenta Oeconomica, Vol. 45 No. 1, pp. 105-139.

16. Merito, M., Giannangeli, S., Bonaccorsi, A. (2010), "Do incentives to industrial R\&D enhance research productivity and firm growth? Evidence from the Italian case", International Journal of Technology Management, Vol. 49 No.1/2/3, pp. 25-48.

17. Mina, A., Di Minin, A., Martelli, I., Testa, G., Santoleri, P. (2021), "Public funding of innovation: Exploring applications and allocations of the European SME Instrument", Research Policy, Vol. 50 No. 1.

18. Ministry of Regional Development CZ (2021), "DotaceEU.cz. European Funds Portal in the Czech Republic", available at: https://www.dotaceeu.cz/en/home-en (15 January 2021)

19. Montmartin, B. A., Herrera, M. (2015), "Internal and external effects of R\&D subsidies and fiscal incentives: Empirical evidence using spatial dynamic panel models", Research Policy, Vol. 44 No. 5, pp. 1065-1079. 
20. Neméthová, V., Širanová, M., Šipikal, M. (2019), "Public support for firms in lagging regions - evaluation of innovation subsidy in Slovakia", Science \& Public Policy, Vol. 46 No. 2, pp. 173-183.

21. OECD (2005), Oslo manual. The Measurement of Scientific and Technological Activities, Proposed Guidelines for Collecting and Interpreting Technological Innovation Data, 3rd edition, Paris, OECD.

22. Segarra-Blasco, A., Garcia-Quevedo, J., Tervel-Carrizosa, M. (2008), "Barriers to innovation and public policy in Catalonia", International Entrepreneurship and Management Journal, Vol. 4 No. 4, pp. 431-451.

23. Woolthuis, R. K., Lankhuizen, M., Gilsing, V. (2005), "A system failure framework for innovation policy design", Technovation, Vol. 25 No. 6, pp. 609-619.

24. Zakić, N., Popović, J., Miškić, M. (2020), "The Linkages Between Investments in Innovation and Business Performance in Serbia", Management: Journal of Sustainable Business and Management Solutions in Emerging Economies, Vol. 25 No. 3, pp. 1-1 1.

\section{About the authors}

Viktorie Klímová works as the associate professor at Masaryk University, Faculty of Economics and Administration, Department of Regional Economics and Administration. Her research focuses on the implementation of innovation policy in EU countries and the role of policymakers and institutions in the innovation environment. She participated in research and developmental projects financed by national and European resources. The author can be contacted at email vikłorie.klimova@econ.muni.cz

Vladimír Žítek works as the associate professor and department head at Masaryk University, Faculty of Economics and Administration, Department of Regional Economics and Administration. His research interests are the functioning of regional innovation systems and territorial disparities in economic activity. He participated in research and developmental projects financed by national and European resources. The author can be contacted at email vladimir.zitek@econ.muni.cz

Tereza Lelková is a PhD. Student in Regional Economics and the instructor at Masaryk University, Faculty of Economics and Administration, Department of Regional Economics and Administration. Her research interests are innovation policy, particularly the innovation policy aimed at solving societal challenges. The author can be contacted at email tereza.lelkova@econ.muni.cz 